\title{
Design of Hybrid Suspension System for Automotive Applications
}

\author{
P.Nagaraju ${ }^{*}, 1$, P.H.V.Sesha Talpa Sai ${ }^{2}$, Y. Vijay Kumar ${ }^{1}$, C.Udayakiran ${ }^{1}$ \\ ${ }^{I}$ Department of Mechanical Engineering, J.B.Institute of Engineering and Technology, Hyderabad, India- \\ 500072. \\ ${ }^{2}$ Department of Mechanical Engineering, Centre for Innovation, Incubation \& Entrepreneurship (CIIE), \\ Malla Reddy College of Engineering \& Technology, Dhulapally, Secunderabad.
}

\begin{abstract}
Comfort travel is order of the day for any automotives in spite of the road conditions. Suspension system holds whole and sole responsibility of providing comfort to the occupants. Intensity of the disturbance originated from road varies with its condition ranging from minimum in case of normal road (Moderately rough) to maximum in case of pot hole or speed breaker. Accordingly stiffness of the suspension system needs to vary which is not so with today's configuration. To provide solution to this problem a hybrid design has been evolved which will have provision for change over option between two springs with different stiffness values. To start with all the subsystems of the proposed design are identified and sizing of each is evolved through design. Further design adequacy has been assessed through Finite Element Analysis.
\end{abstract}

Keywords: Suspension system, Hybrid system, Stiffness, Cyclic motion, Automobile, Shock loads.

\section{Introduction}

During its course of application any automobile vehicle experiences low intensity cyclic motion (Vibration) while passing over normal road and the same experiences high intensity cyclic motion (Shock) while passing over pot hole or speed breaker. Vehicle will be equipped with suspension system so as to provide comfort for the passengers against these two adverse conditions as shown in Figure 1.

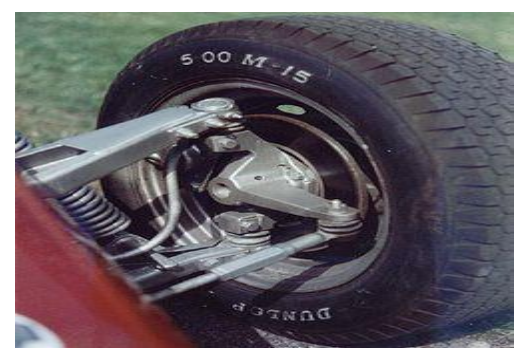

Figure 1. Suspension system

In spite of having suspension system, very often passengers notice discomfort, extent of which will be relatively high when vehicle moves on pot hole or speed breaker. Hence it is decided to explore the possibility of improving the design of suspension system to address the aforementioned problem.

Design of suspension system has been aimed for FSRTE02 chassis considering the desired car handling and the regulations determined by the Formula Student organization. The suspension properties are set for optimum road holding. Front and rear roll stiffness is added using helical springs. A motorcycle steering damper is used for roll damping [1]. Two different suspension systems have been designed for front and rear. Light weight, compact design and coil-over dampers are chosen.

These systems can be mounted in any desired orientation, because they are pressurized with nitrogen gas to avoid cavitations. The minimum stroke of the dampers is $29 \mathrm{~mm}$. The front and rear coil springs are identical [2]. Another paper is found on design of suspension components for a Formula SAE car. In order to reduce weight, spherical bearings are staked into the pivot points and ball joints of the lower control arms, along with the rear upper control arm pivot points and front upper control arm ball joints instead of using traditional heavier rod ends at these locations [3]. More focus is given on material selection for suspension systems used in UTEP Mini-Baja vehicle. There is a huge range of different properties that can be achieved with the use of engineering materials, from composites to many different alloys. They focused in three major goals while trying to find the best material that meet their needs, such goals are: the material deformation with several impacts, the cost of the material, and manufacturability [4]. It is brought out that even with the rapidly evolving computational tools available today, suspension design remains very much a black art. This is especially true with respect to road cars because there are so many competing design objectives. In most of the cases some of these objectives may be neglected. Even still, just concentrating on maximizing road-holding capability remains 
a formidable task. Procedure for establishing suspension parameters is outlined and includes a computational example that entails spring, damper, and anti-roll bar specification. The procedure is unique in that it not only covers the prerequisite vehicle dynamic equations, but also outlines the process that sequences the design evolution. The model presented embraces the latest trends with respect to vehicle dynamics. Special emphasis, including discussion of theory and analysis, is placed on damper specification [5].

From the literature survey it is clearly evident that almost no work has been done on improving the design of suspension system to provide comfort against two different road conditions.

\section{Design Philosophy}

Vehicle mounted on suspension system can be idealized as single Degree Of Freedom (DOF) system [6] as shown in Figure 2.

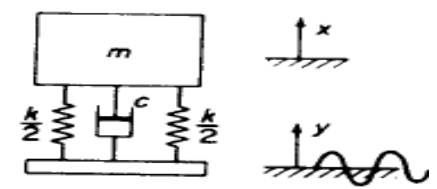

Figure 2. Mathematical model of the vehicle

In the above figure ' $m$ ' represents the mass of vehicle along with passengers. ' $K$ ' represents stiffness of spring in suspension system and ' $\mathrm{C}$ ' represents damping of damper (Hydraulic/Pneumatic) located in suspension system. With the mounted mass, spring with its stiffness contributes for the frequency of suspension system. ' $\mathrm{Y}$ ' represents the base excitation originated from road and ' $\mathrm{X}$ ' represents the motion transmitted to the vehicle. Suspension system will be considered as effective when $\mathrm{X}$ is much less than $\mathrm{Y}$. When vehicle passes over normal road it experiences vibration and for this case relation between motion ratio (i.e. $\mathrm{X} / \mathrm{Y}$ ) and frequency ratio [6] is shown in Figure 3.

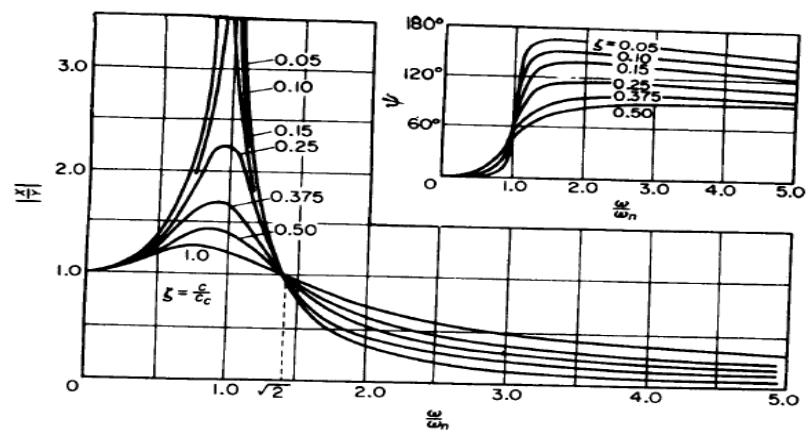

Figure 3. Relation between motion ratio and frequency ratio

In this figure ' $\omega$ ' represents frequency of excitation originating from road and ' $\omega_{\mathrm{n}}$ ' represents desired frequency of spring.

From the above figure it is clearly evident that

$$
\begin{gathered}
\text { For } X<Y \\
\frac{\omega}{\omega_{n}}>\sqrt{2}
\end{gathered}
$$

which means that frequency of spring should be less than that of 0.707 times the frequency of excitation, so as to have comfort when vehicle passes over normal road.

When the same vehicle passes over pot hole or speed breaker it experiences shock and for this case relation between motion ratio (i.e. X/Y) and frequency ratio [7] is shown in Figure 4. 


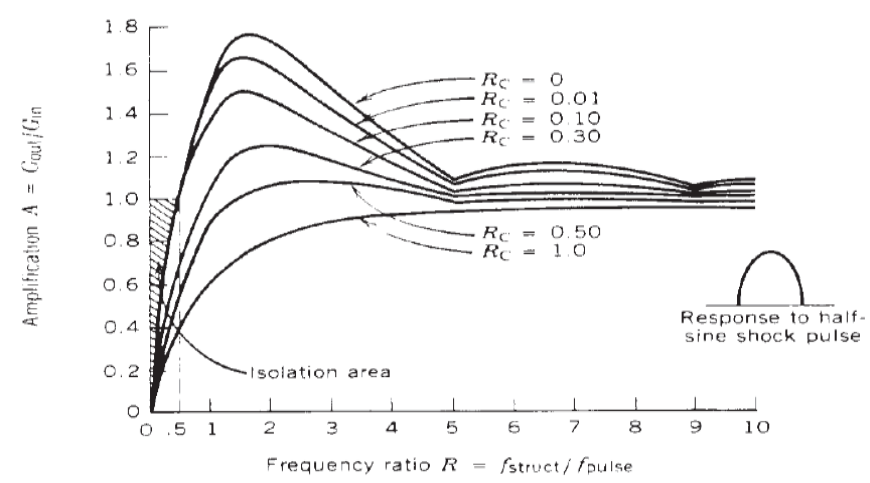

Figure 4. Relation between motion ratio and frequency ratio

From the above figure it is clearly evident that frequency of the spring should be less than 0.5 times the frequency of excitation so as to have comfort against shock.

Hence frequency of the spring for isolating shock should be less than that of vibration which means spring meant for shock (With low frequency) as well isolate vibration. But at low frequency dynamic displacement and subsequently stress experienced by the spring will be very high. Hence spring having low frequency can't be chosen for attacking vibration and shock simultaneously rather spring with low frequency should be taken only by compulsion i.e. for shock. Moreover vehicle will come across normal road very often (i.e. vibration) and pothole or speed breaker rarely. Hence it is proposed to come up with a hybrid design which will facilitate to have a change over between low and high values of stiffness as and when situation demands. Further damper in conventional design is dispensed with by choosing shape memory alloy for spring as it possesses very good damping characteristics.

Proposed design with all subsystems is shown in Figure 5.

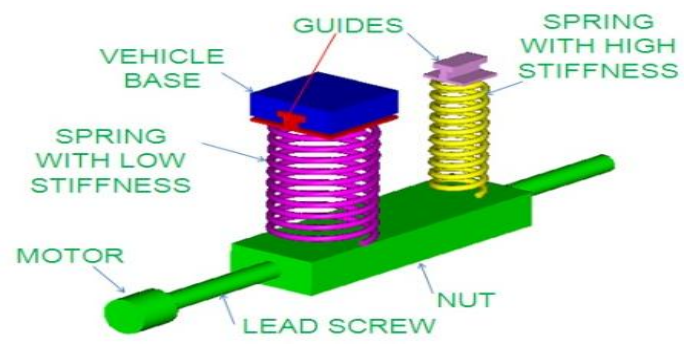

Figure 5. Proposed design

In this design spring $1 \& 2$ are integral to nut (Bottom side). Guides are integral to springs (Top side). Rotary motion of lead screw gets converted into linear motion of nut and in turn spring $1 \& 2$. Motor can be rotated in both clock wise and anti clock wise \& accordingly nut moves both in left hand side and right hand side. When vehicle has to cross pot hole or speed breaker spring 1 will be engaged between vehicle base and nut. Nut is attached to axle through guides (Not shown here). When vehicle has to pass over normal road driver operates the motor which rotates lead screw with which nut moves towards motor with which spring 1 gets disengaged and spring 2 gets engaged with vehicle base.

From the above figure the following components are identified for which detailed design is carried out.

- Lead screw

- Motor

- Spring for normal road

- Spring for pot hole or speed breaker

- Guides

- Bearing

\section{Design Configuration}

Following design inputs are considered.

- Maximum axial motion of mass $=1 \mathrm{~m}$

- $\quad$ Time taken for motion $=3$ seconds

- Time to achieve velocity $=0.5 \mathrm{sec}$

Outcome of design is summarized in Table 1. 
Table 1: Design parameters

\begin{tabular}{|c|c|c|}
\hline Sl. No. & Design Parameter & Value \\
\hline \multicolumn{3}{|c|}{ Lead Screw } \\
\hline 1. & Diameter & $35 \mathrm{~mm}$ \\
\hline 2. & Length & $1000 \mathrm{~mm}$ \\
\hline \multicolumn{3}{|c|}{ Motor for Lead Screw } \\
\hline 1. & Torque & $2 \mathrm{~N}-\mathrm{m}$ \\
\hline 2. & Power & $0.5 \mathrm{HP}$ \\
\hline \multicolumn{3}{|c|}{ Spring for normal road } \\
\hline 1. & Wire diameter & $4.45 \mathrm{~mm}$ \\
\hline 2. & Mean coil diameter & $13.4 \mathrm{~mm}$ \\
\hline 3. & Natural frequency & $10 \mathrm{~Hz}$ \\
\hline \multicolumn{3}{|c|}{ Spring for speed breaker/pot hole } \\
\hline 1. & Wire diameter & $4.45 \mathrm{~mm}$ \\
\hline 2. & Mean coil diameter & $13.4 \mathrm{~mm}$ \\
\hline 3. & Natural frequency & $8 \mathrm{~Hz}$ \\
\hline \multicolumn{3}{|l|}{ Guides } \\
\hline 1. & Dynamic load & $84.5 \mathrm{~N}$ \\
\hline 2. & Cross section & $\mathrm{T}$ \\
\hline \multicolumn{3}{|l|}{ Bearing } \\
\hline 1. & Outer diameter & $100 \mathrm{~mm}$ \\
\hline 2. & Width & $25 \mathrm{~mm}$ \\
\hline 3. & Designation & 6407 \\
\hline
\end{tabular}

\section{Structural Analysis}

Structural analysis of hybrid suspension system is carried out using Finite Element Method (FEM) in ANSYS software. The objective of the structural analysis is to assess the design adequacy against the functional load.

Structural analysis is carried out against the weight of mounted system and obtained maximum Von Misses stress. Maximum stress thus obtained is compared with allowable stress and obtained the available factor of safety.

\section{Criteria}

$\underline{\text { Static analysis }}$

- $\quad$ Minimum available factor of safety should be more than the desired factor of safety (1.5).

Modal analysis

- $\quad$ First natural frequency should be above the frequency associated with spring i.e. $10 \mathrm{~Hz}$.

To begin with geometric model of the intended design is built in 3D CAD software from its dimensions. However load bearing members are only considered for analysis. Then geometric model is converted into FE model by discretizing with elements. Springs and lead screw are discretized with linear beam (BEAM4) elements and nut is discretized with solid (SOLID45) elements. As springs are made of shape memory alloy and all other subsystems are made of steel, accordingly material properties are considered for the analysis. FE model is constrained at two extreme corners where supports are provided on the lead screw. FE model with boundary conditions is shown in figure 6 .

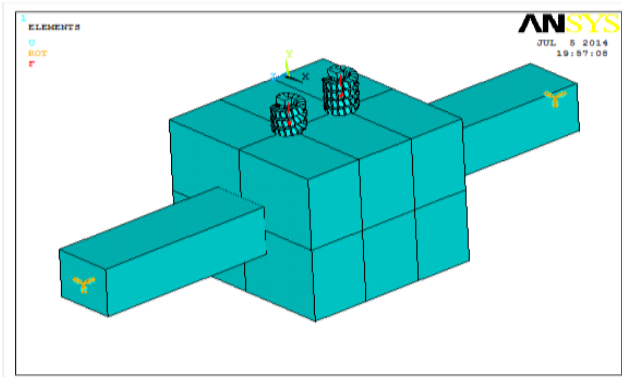

Figure 6. FE model

Static analysis was carried out and then dynamic (Modal) analysis was also carried out. Modal analysis is the study of the dynamic properties of structures under vibration excitation. In structural engineering, modal analysis uses a structure's overall mass and stiffness to find the various periods that it will naturally resonate at. A modal analysis calculates the undamped natural modes of a system. These modes are given in decreasing order of period and are numbered starting from 1. Von Misses stress plot and mode shape plot corresponding to first natural frequency are shown in Figure 7. 
Von misses stress $=380 \mathrm{MPa}$

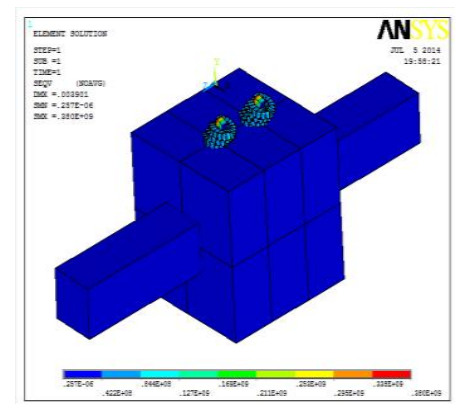

First Natural Frequency $=417 \mathrm{~Hz}$

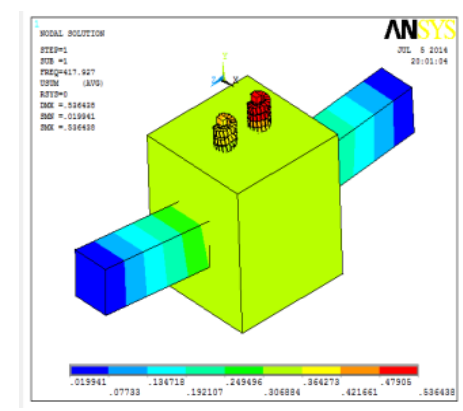

Figure 7. Stress and mode shape plots

\section{Results And Discussion}

Outcome of analyses is summarized in Table 2.

Table 2: Analyses results

\begin{tabular}{|c|c|c|c|c|}
\hline $\begin{array}{l}\text { Sl. } \\
\text { No }\end{array}$ & Result & $\begin{array}{l}\text { Maximu } \\
\text { m } \\
\text { Value }\end{array}$ & $\begin{array}{l}\text { Allowable } \\
\text { value }\end{array}$ & $\begin{array}{l}\text { Factor of } \\
\text { safety }\end{array}$ \\
\hline \multicolumn{5}{|c|}{ Static } \\
\hline 1. & $\begin{array}{l}\text { Von } \\
\text { Misses } \\
\text { stress }\end{array}$ & 380 & $1256 \mathrm{MPa}$ & 3.3 \\
\hline \multicolumn{5}{|c|}{ Modal } \\
\hline 2. & $\begin{array}{l}\text { First } \\
\text { natural } \\
\text { frequency }\end{array}$ & $417 \mathrm{~Hz}$ & $>10 \mathrm{~Hz}$ & -- \\
\hline
\end{tabular}

- Maximum Von Misses stress is observed to be $380 \mathrm{MPa}$.

- Available factor of safety is observed to be 3.3 which is more than minimum desired factor of safety (1.5). Hence the design is safe.

- Frequency of the intended system corresponding to first bending mode is found to be $417 \mathrm{~Hz}$ which is much above the frequency associated with spring i.e. $10 \mathrm{~Hz}$. Hence system doesn't experience resonance.

\section{Conclusion}

A hybrid design of suspension system has been brought out which will facilitate to have a change over between low and high values of stiffness as and when situation demands. Further damper in conventional design is dispensed with by choosing shape memory alloy for spring as it possesses very good damping characteristics. Design adequacy of the configuration is assessed with the aid of FE analysis which conveyed a message that the design is safe.

\section{Acknowledgment}

The authors sincerely acknowledge the valuable support extended by Dr. Devarayapalli Kamakshaiah Charyulu, Professor \& Head of the Science and Humanities Department, Bhaskar Engineering College, Hyderabad, India. The authors thank Dr. Niraj Upadhaya, Principal, J B Institute of Engineering and Technology, Hyderabad, India for the support.

\section{References}

[1]. van Berkum, "Chassis and suspension design FSRTE02”, Master's Thesis, Eindhoven, March 2006.

[2]. P.C.M. van den Bos,, "Design of a Formula Student Race Car Spring-Damper System”, Master traineeshipEindhoven, March, 2010.

[3]. Badih A. Jawad and Brian D. Polega, "Design of Formula SAE Suspension Components", Proceedings of the 2002 SAE Motorsports Engineering Conference and Exhibition (P-382), December 2-5, 2002.

[4]. Cesar, "Minibaja vehicle front suspension design" Technical report, 2011.

[5]. David E. Woods, "Numerical Design of Racecar Suspension Parameters", SAE Government/Industry Meeting, April 26-28, 1999.

[6]. W.T. Thomson, "Theory of vibration with applications".

[7]. Dave S. Steinberg, "Vibration analysis of electronic equipment". 